\title{
A DEMOCRATIZAÇÃO DA GESTÃO EDUCACIONAL E ESCOLAR: UM OLHAR NOS SISTEMAS MUNICIPAIS DE ENSINO
}

\section{The democratization of educational and school management: a view in the municipal education systems}

\author{
Marília do Nascimento Moraes ${ }^{1}$ \\ Marilene Gabriel Dalla Corte ${ }^{2}$
}

\begin{abstract}
Resumo: O texto contempla um mapeamento sobre as produções científicas relacionadas à democratização da gestão educacional e escolar no Brasil, desenvolvidas no período de 2010 a 2019. Objetiva compreender quais são e o que sinalizam as produções científicas que abordam a democratização da gestão educacional e escolar no Brasil, considerando suas contribuições acerca dos mecanismos de criação e fortalecimento dos Sistemas Municipais de Ensino. Tratase de uma pesquisa de natureza qualitativa, a partir do estado do conhecimento, utilizando-se de um estudo exploratório de produções científicas e referenciais teóricos, bem como de análise bibliométrica. Os resultados indicam que as produções do período de 2010 a 2019, independentemente de suas especificidades, abordam que a gestão democrática ainda caminha a passos lentos para a sua efetivação, porém mencionam a importância dos princípios e mecanismos de democratização da gestão para a necessária e efetiva participação da comunidade intra e extraescolar na implementação de políticas públicas próprias para melhorar a autonomia dos espaços de gestão educacional e escolar.
\end{abstract}

Palavras-chave: Gestão Democrática. Gestão Educacional e Escolar. Políticas Públicas. Sistemas Municipais de Ensino.

Abstract: The article presents a mapping of scientific productions related to the democratization of educational and school management in Brazil, developed between 2010 and 2019. The research approaches issues observed in these scientific productions and their contributions concerning the foundation and improvement of Municipal Education Systems. The main purpose of this article is to identify the scientific productions related to the subject "democratization of educational and school management in Brazil", considering their contributions concerning the foundation and improvement of Municipal Education Systems. This research follows a qualitative approach, based on the state of knowledge, using the exploratory study of scientific productions and theoretical references as well as bibliometric analysis. The results revealed that scientific productions developed between 2010 and 2019,

\footnotetext{
${ }^{1}$ Graduada e licenciada em Letras Espanhol e respectivas literaturas pela Universidade Federal de Santa Maria (2016). Especialização em Gestão Educacional pela Universidade Federal de Santa Maria (2020) e atualmente cursa o mestrado profissional no Programa de Pós-Graduação em Políticas Públicas e Gestão Educacional na Universidade Federal de Santa Maria-UFSM.ORCID: https://orcid.org/0000-0001-7036-8757. E-mail: $<$ nmarilia91@gmail.com>.

${ }^{2}$.Doutora e pós-doutora em Educação. Professora Associada no Departamento de Administração Escolar do Centro de Educação, da Universidade Federal de Santa Maria. Líder do Gestar/CNPq - Grupo de Estudos e Pesquisas em Políticas Públicas e Gestão Educacional. ORCID: https://orcid.org/0000-0001-8272-2944. E-mail: $<$ marilenedallacorte@gmail.com>.
} 
regardless of their specificities, inform that the implementation of democratic management is still developing slowly. However, they also mention the importance of principles and of management democratization mechanisms for necessary and effective participation of internal and external school communities in the policy implementation of their policies to improve the autonomy of educational and school management spaces.

Keywords: Democratic Management. Educational and School Management. Public Policies. Municipal Education Systems.

\section{Introdução}

O artigo decorre dos estudos realizados junto ao Programa de Pós-graduação em Políticas Públicas e Gestão Educacional (PPPG) da Universidade Federal de Santa Maria (UFSM), e no bojo dos estudos do Grupo de Pesquisa em Políticas Públicas e Gestão Educacional (Gestar/CNPq), com destaque para as políticas de democratização da gestão educacional e escolar no contexto da Educação Básica no Brasil.

Afirma-se a necessidade da qualidade da educação no âmbito escolar e, nesta ótica, a Constituição Federal de 1988 estabeleceu que a educação, como um direito de todos e dever do Estado e da família, e requer ser promovida e incentivada com a colaboração da sociedade visando o desenvolvimento do sujeito, seu preparo para o exercício da cidadania e sua qualificação para o trabalho (BRASIL, 1988). A realidade educacional brasileira leva a refletir sobre diversos pontos, entre eles a autonomia das instituições escolares que, de acordo com a legislação pertinente, possuem liberdade para constituir espaços de democratização nas dimensões administrativa, pedagógica e financeira e, consequentemente, aprimorar os processos educacionais de maneira compartilhada, colaborativa e participativa.

A qualidade pensada no âmbito da gestão escolar não se restringe apenas à figura do gestor, mas se dispõe a alcançar todos os segmentos da comunidade escolar. Para Libâneo (2001, p. 54) a educação de qualidade,

[...] é aquela que promove para todos o domínio de conhecimentos e o desenvolvimento de capacidades cognitivas, operativas e sociais necessários ao atendimento de necessidades individuais e sociais dos alunos, à inserção no mundo do trabalho, a constituição da cidadania, tendo em vista a construção de uma sociedade mais justa e igualitária.

Nessa perspectiva, o autor defende que haja qualidade social na escola, viabilizando condições adequadas que incluam socialmente todos os sujeitos, potencializando efetiva educação integral.

Este estudo, além de focar discussões decorrentes de produções científicas, priorizou mapear e refletir sobre a realidade das redes de ensino municipais, enfatizando os princípios da gestão democrática e a escola a partir de suas singularidades. Pesquisas deste viés contribuem para repensar os contextos escolares e, especialmente, as políticas educacionais que perpassam estes espaços, considerando a necessária apropriação das mesmas para sua efetiva execução na democratização destes contextos.

A pesquisa realizada, a partir do estado do conhecimento, sobre a criação e fortalecimento dos sistemas municipais de ensino, tornou-se pertinente para traçar um olhar específico em contextos singulares que ainda não constituíram Sistema Municipal de Ensino (SME), com vistas a colaborar com processos de criação e implantação de SME. 
Assim, este estudo apresenta uma síntese da pesquisa realizada com base na metodologia exploratória do estado do conhecimento balizada pelo seguinte problema: o que sinalizam as produções científicas do período de 2010 a 2019, relacionadas à democratização da gestão educacional e escolar no Brasil, em especial, quanto a criação e ao fortalecimento dos Sistemas Municipais de Ensino? Objetivou-se, portanto, compreender no arcabouço de produções científicas do período de 2010 a 2019, quais elementos constituem o cenário da democratização da gestão educacional e escolar no Brasil, em especial, no que se refere à criação e ao fortalecimento dos Sistemas Municipais de Ensino.

O artigo está organizado em seções, as quais destaca-se primeiramente os aspectos metodológicos da pesquisa, em que são teorizados os processos de construção e análise de dados com base em Gil (2010), Morosini (2014) e Flick (2013). Na segunda seção, contextualiza-se os princípios básicos que fundamentam a gestão democrática educacional e escolar no Brasil, apresentando os achados do estado do conhecimento inter-relacionados à democratização dos espaços educacionais. Na terceira seção, aborda-se os mecanismos de democratização no contexto da gestão educacional, relacionados aos Sistemas Municipais de Ensino. Na quarta seção, destaca-se a criação e o fortalecimento dos Sistemas Municipais de Ensino na perspectiva da gestão democrática, trazendo as realidades locais encontradas por meio da busca realizada nas produções científicas. Por fim, apresenta-se as considerações finais acerca das aprendizagens entrelaçadas à problemática e aos propósitos da pesquisa.

\section{Aspectos metodológicos e dados preliminares da pesquisa}

A base teórico-metodológica de pesquisa consistiu na abordagem qualitativa de acordo com Flick (2013), configurando-se pelo estado do conhecimento (MOROSINI, 2014) de cunho exploratório intermediado por procedimentos bibliográficos e bibliométricos. Encontrou-se em Gil (2010, p. 71) que a pesquisa do tipo exploratória "[...] é desenvolvida com base em material já elaborado, constituído principalmente de livros e artigos científicos", e este tipo de estudo é desenvolvido com a finalidade de possibilitar ao pesquisador uma visão ampla e, ao mesmo tempo, delimitada acerca da realidade. Assim, o estudo exploratório priorizou enriquecer o banco de dados sobre o tema pesquisado e, também, proporcionar a formulação de novos conceitos contemplando a base de conhecimento produzida sobre democratização da gestão educacional e escolar no Brasil.

Morosini (2014, p. 155) apresenta contribuições sobre a pesquisa do estado do conhecimento: "[...] identificação, registro, categorização que levem à reflexão e síntese sobre a produção científica de uma determinada área, em um determinado espaço de tempo, congregando periódicos, teses, dissertações e livros sobre uma temática específica". Além disso, a autora afirma que "[...] faz-se necessário considerar que a construção de uma produção científica está relacionada não só à pessoa/pesquisador que a produz, mas a influências da instituição na qual está inserida, do país em que vive e de suas relações com a perspectiva global” (Ibidem, p. 156). Para tanto, a pesquisa desenvolvida priorizou o âmbito das produções científicas acerca da gestão na Educação Básica, mais especificamente, os Sistemas Municipais de Ensino.

O corpus de pesquisa foi composto por trabalhos apresentados na base de dados da Biblioteca Digital Brasileira de Teses e Dissertações (BDTD), uma vez que esta base possui um amplo espectro de publicações relacionadas às Ciências Humanas, com ênfase na área da Educação, sendo, por isso, escolhida como a base de dados que se adequa aos propósitos do estudo desenvolvido. A busca foi determinada com o filtro no período de 2010 a 2019, 
justamente porque levou-se em consideração o fato de haver poucas produções publicadas num período de menor tempo. Conforme Figura 1, os descritores definidos para esta pesquisa foram:

Figura 1 - Descritores de busca do estado do conhecimento

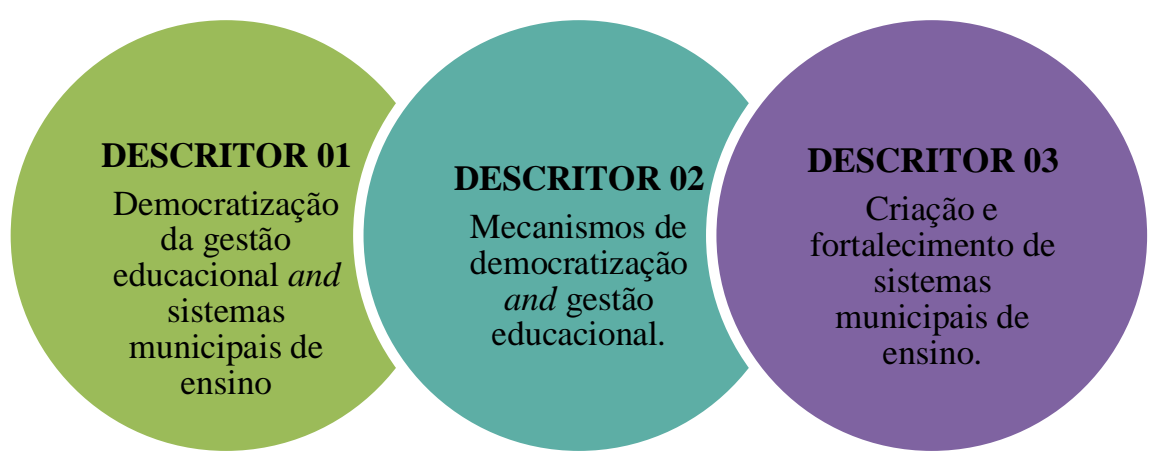

Fonte: Elaborado pelas autoras (2021) .

$\mathrm{Na}$ busca por títulos de teses e dissertações na BDTD encontrou-se: descritor 1 - oito trabalhos dos quais foram selecionados seis; descritor 2 - 22 trabalhos dos quais foram selecionados oito; descritor 3 - 56 trabalhos e destes selecionados seis, retratados no Gráfico 1.

Gráfico 1 - Dados quantitativos de busca por títulos

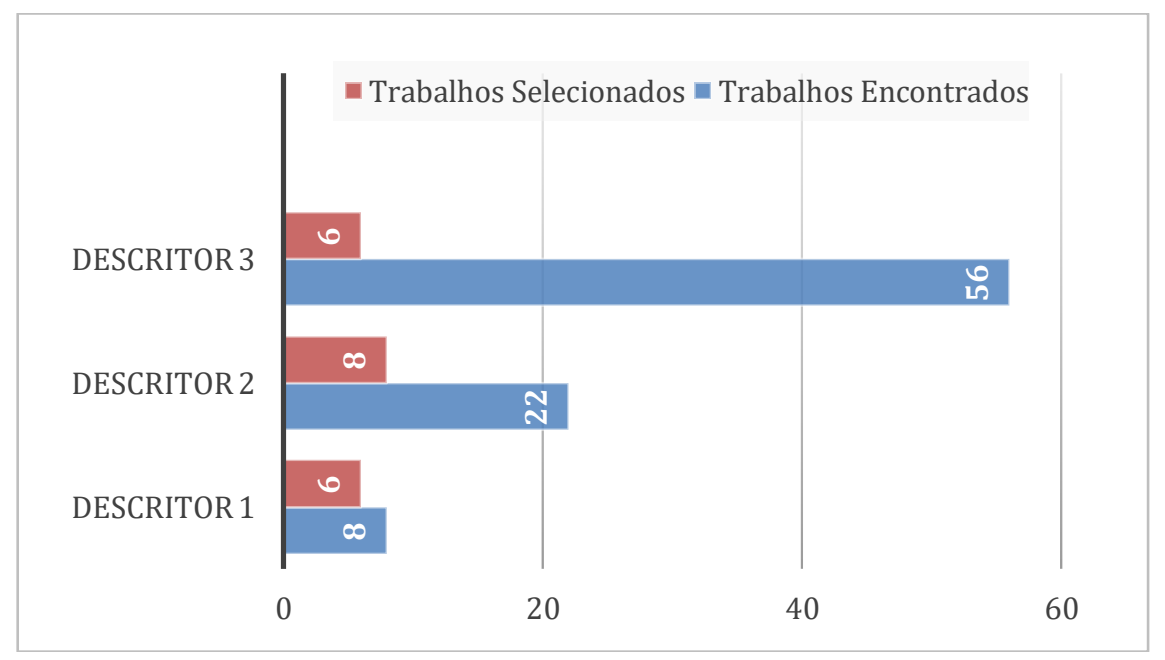

Fonte: Elaborado pelas autoras (2021).

Considerando as 86 produções científicas encontradas, entre teses e dissertações, foram classificadas e analisadas 20 obras, nas quais se observou como o tema é abordado, a aderência da temática para este estudo, a metodologia utilizada, os resultados e contribuições apresentados. Para chegar aos 20 trabalhos selecionados alguns critérios serviram como parâmetros: a) os trabalhos deveriam ser relacionados à temática da Educação Básica municipal; b) abordar princípios e mecanismos de gestão democrática nos Sistemas Municipais de Ensino; c) tratar da criação de Sistemas Municipais de Ensino. Os trabalhos que não foram 
selecionados se referiam a outras temáticas, tais como educação inclusiva, Educação Superior ou gestão nas Redes Estaduais de Ensino.

Com vistas a potencializar a visualização dos trabalhos selecionados e analisados, na Tabela 1 está disposta uma visão geral dos indicadores por ano de publicação e respectivo descritor das 20 produções científicas selecionadas.

Tabela 1 - Visão geral dos trabalhos selecionados no período de 2010 a 2019

\begin{tabular}{|c|c|c|c|c|}
\hline \multirow[b]{2}{*}{ ANO } & \multicolumn{3}{|c|}{ DESCRITORES } & \multirow[b]{2}{*}{$\begin{array}{c}\text { TOTAL } \\
\text { GERAL } \\
\text { POR ANO }\end{array}$} \\
\hline & $\begin{array}{l}\text { 1. Democratização } \\
\text { da Gestão } \\
\text { Educacional and } \\
\text { Sistemas Municipais } \\
\text { de Ensino }\end{array}$ & $\begin{array}{l}\text { 2. Mecanismos de } \\
\text { Democratização and } \\
\text { Gestão Educacional }\end{array}$ & $\begin{array}{l}\text { 3. Criação e } \\
\text { Fortalecimento } \\
\text { and Sistemas } \\
\text { Municipais de } \\
\text { Ensino }\end{array}$ & \\
\hline 2010 & 3 & 2 & 1 & 6 \\
\hline 2011 & 1 & 0 & 1 & 2 \\
\hline 2012 & 0 & 1 & 1 & 2 \\
\hline 2013 & 0 & 1 & 0 & 1 \\
\hline 2014 & 0 & 0 & 0 & 0 \\
\hline 2015 & 0 & 0 & 0 & 0 \\
\hline 2016 & 1 & 1 & 0 & 2 \\
\hline 2017 & 0 & 1 & 0 & 1 \\
\hline 2018 & 1 & 1 & 2 & 4 \\
\hline 2019 & 0 & 1 & 1 & 2 \\
\hline $\begin{array}{l}\text { TOTAL POR } \\
\text { DESCRITOR }\end{array}$ & 6 & 8 & 6 & 20 \\
\hline
\end{tabular}

Fonte: Elaborado pelas autoras (2021).

Entre os trabalhos selecionados por ano, destacam-se os anos de 2010 e de 2018 com mais publicações. Em 2010 foram seis publicações, sendo que destas, três tratam sobre a democratização da gestão educacional e dos SME. Em 2018 foram quatro publicações, duas delas voltadas à temática sobre criação e fortalecimento dos SME. Analisando os números pode-se perceber que nos demais anos houve oscilação no número de publicações, porém, a partir de 2016 houve nove publicações que priorizaram referenciar o Plano Nacional de Educação (PNE) em suas prioridades e estratégias para a democratização da gestão educacional e escolar no Brasil.

Acredita-se que esta movimentação está relacionada à aprovação do Plano Nacional de Educação no ano de 2014 que enfatiza a importância da criação de Sistemas Municipais de Ensino, por meio da Lei n. 13.005/2014 (BRASIL, 2014). Este cenário contribuiu para instituir mudanças nos processos de gestão e a organização de órgãos deliberativos como os Conselhos Municipais de Educação (CME), fato este que é um marco para as administrações municipais e uma oportunidade de suas redes de ensino tornarem-se autônomas.

No Gráfico 2, consta o percentual de trabalhos analisados de acordo com cada região do Brasil. Nesse sentido, observou-se que grande parte das pesquisas foram realizadas na região nordeste no Brasil. 
Gráfico 2 - Trabalhos selecionados por região do Brasil

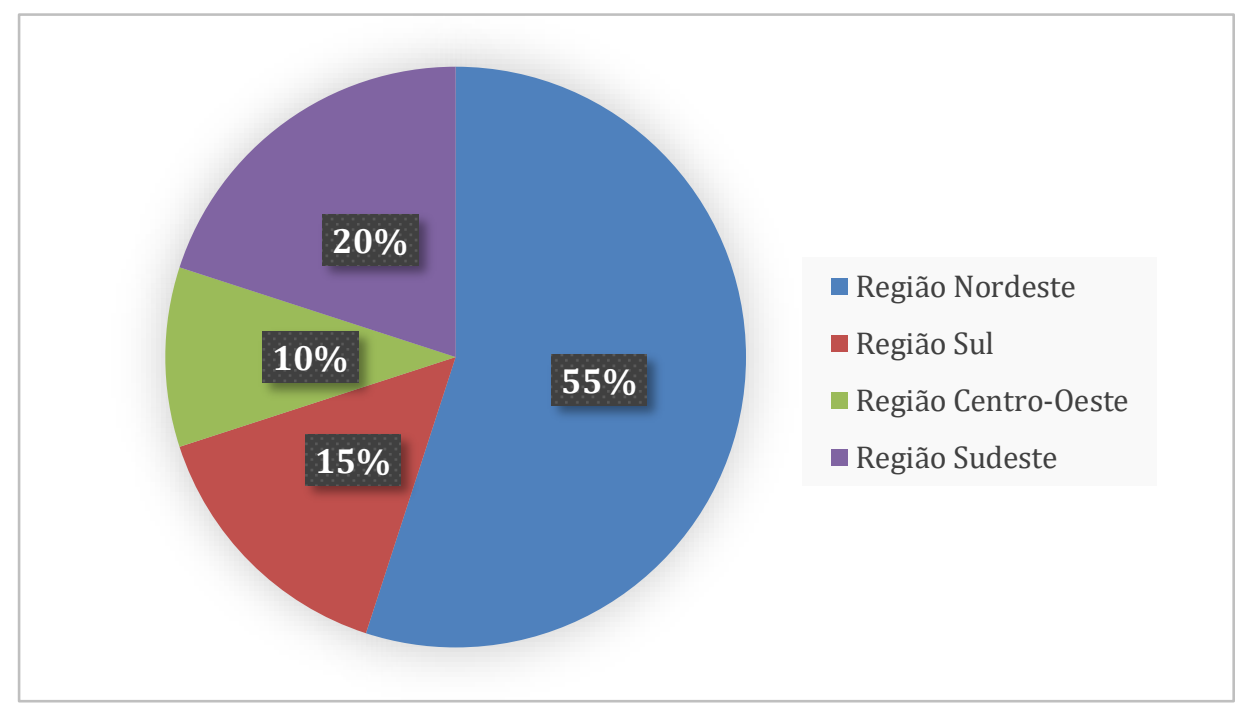

Fonte: Elaborado pelas autoras (2021).

Verificou-se que a região nordeste do Brasil apresenta mais da metade das pesquisas publicadas quanto a esta temática e, neste universo, destacam-se as Universidades Federais na pesquisa científica na área da educação. Entre as instituições cita-se: Universidade Federal do Rio Grande do Norte (UFRN) - quatro trabalhos; Universidade Federal da Paraíba (UFPB)- três trabalhos; Universidade Federal da Bahia (UFBA) - dois trabalhos; Universidade Federal do Maranhão (UFMA) - dois trabalhos; Universidade Federal de Pernambuco (UFPE) - um trabalho.

Por fim, destaca-se que para trabalhar os dados construídos pela metodologia do estado do conhecimento, optou-se pela análise de conteúdo a qual, segundo Flick (2013, p. 134), “[...] tem por objetivo classificar o conteúdo dos textos alocando as declarações, sentenças ou palavras a um sistema de categorias". Nessa lógica, para a constituição do corpus de análise, priorizou-se dissertações e teses que se encaixassem nas categorias estabelecidas as quais são decorrentes dos três descritores de busca, tornando-se possível identificar nos textos selecionados quais temáticas abordavam especificamente e quais contribuições cada uma trouxe para a problemática e objetivo de pesquisa, conforme consta na seção a seguir.

\section{A democratização no âmbito da gestão educacional e escolar}

O conceito de gestão escolar efetivou seu espaço na sociedade após a aprovação da Constituição Federal de 1988, que dispõe no Art. 206 sobre a "gestão democrática do ensino público na forma da lei" (BRASIL, 1988). A partir daí, surge na Lei de Diretrizes e Bases da Educação Nacional (LDBEN) n. 9.394/96, Art. 14, de forma mais específica, a gestão democrática como um dos seus princípios, sugerindo que se dê por meio de trabalho coletivo e participativo nos contextos da gestão educacional e escolar (BRASIL, 1996).

Para Libâneo (et al., 2008, p. 101) o conceito de gestão se refere a “[...] atividade pela qual são mobilizados os meios e procedimentos para atingir os objetivos da organização, envolvendo, basicamente, os aspectos gerenciais e técnico-administrativos". O uso recorrente das nomenclaturas "gestão democrática" e "democratização da educação" se fortaleceu com as 
legislações educacionais e, principalmente, com as transformações do papel dos gestores nos espaços educacionais. De forma geral,

A gestão educacional corresponde ao processo de gerir a dinâmica do sistema de ensino como um todo e de coordenação das escolas em específico, afinado com as diretrizes e políticas educacionais públicas para a implementação das políticas educacionais e projetos pedagógicos das escolas, compromissado com os princípios da democracia e com métodos que organizem e criem condições para um ambiente educacional autônomo. (LUCK, 2006, p. 35-36).

Durante o estudo evidenciou-se alguns princípios fundamentais para o processo de democratização e, assim sendo, tornou-se possível inter-relacionar alguns deles para a consecução desse processo no cenário da gestão educacional e escolar: participação, coletividade, transparência, descentralização, autonomia, entre outros já mencionados na legislação educacional e em obras decorrentes de pesquisas subjacentes às políticas públicas e processos de gestão da educação.

Ressalta-se que a participação nos processos de gestão necessita ser pensada e articulada de modo a compreender efetivamente o trabalho dos gestores, professores e demais membros da gestão, deliberando e agindo conjuntamente e de maneira descentralizada com relação às diversas situações que surgem no ambiente das secretarias municipais de educação e das instituições escolares entre outros órgãos e instituições. Nessa direção, a gestão qualifica-se pela forma com que seus participantes direcionam suas prioridades e ações em benefício do desenvolvimento dos sistemas/redes de ensino e respectivos órgãos e instituições.

Luck (2002) menciona algumas ações que necessitam ser consolidadas no âmbito dos processos de gestão educacional e escolar, com vistas a mobilizar a participação da comunidade, sendo elas: criar uma visão de conjunto associada a uma ação cooperativa entre os sujeitos; promover um clima de confiança; valorizar as capacidades e aptidões dos participantes; associar/integrar esforços e eliminar divisões; estabelecer demanda de trabalho com o foco nas ideias; e desenvolver a prática de assumir responsabilidades em conjunto.

De forma significativa existem várias formas de participação, uma delas no contexto escolar se dá por meio da escolha para representação de um grupo com determinados objetivos, a exemplo dos Conselhos Escolares, Círculos ou Associações de Pais e Mestres, Grêmios Estudantis, entre outros. A participação colegiada está prevista na LDBN n. 9.394/96, Art. 14:

Art. 14. Os sistemas de ensino definirão as normas da gestão democrática do ensino público na educação básica, de acordo com as suas peculiaridades e conforme os seguintes princípios: I - participação dos profissionais da educação na elaboração do projeto pedagógico da escola; II - participação das comunidades escolar e local em conselhos escolares ou equivalentes. (BRASIL, 1996).

Destaca-se o papel dos gestores, no sentido de coordenar e liderar os processos de gestão de maneira proativa, incentivando a atuação colaborativa dos envolvidos e contribuindo na construção de processos dialógicos e democráticos que prezam pela autonomia e corresponsabilidade. Com base em Vieira (2007, p. 59) a "[...] gestão é arena de interesses contraditórios e conflituosos. Nesse sentido, o gestor que não é um líder em sua área de atuação poderá se deparar com dificuldades adicionais". Então, as ações dos gestores requerem estar associadas diretamente a perspectiva democrática, em que a equipe diretiva, a equipe pedagógica, professores, funcionários, estudantes, pais e/ou responsáveis pelos estudantes, sintam-se comprometidos em trabalhar conjuntamente em processos de gestão mais equitativos, inclusivos, participativos, colaborativos e, sobremaneira, voltados à educação de qualidade. 
Tomando como base os seis trabalhos selecionados no descritor 1 - Democratização da gestão educacional and sistemas municipais de ensino, que tinham como foco a democratização da educação em âmbito municipal, constatou-se que foram enfatizados os espaços de pesquisa, alicerçados nos aspectos das políticas públicas educacionais quanto a legislação nacional e específica de cada município. Constatou-se que os seis trabalhos possuem como ponto em comum a construção de uma linha histórica acerca do percurso das políticas educativas no campo da educação no Brasil, aprofundando a perspectiva dos princípios de democratização da gestão educacional e escolar; também é evidente o fato de serem decorrentes de pesquisas de cunho qualitativo.

Na tese intitulada "Políticas públicas e descentralização: o impacto da municipalização na prática docente", de Nunes (2010), defendida no Programa de Pós-graduação em Educação: Currículo, da Pontifícia Universidade Católica de São Paulo (PUC-SP), aborda-se a questão da municipalização e o seu impacto na prática docente. $O$ autor ressalta que o processo de descentralização nada mais é do que a mudança de responsabilidade de uma esfera para outra, resultando em uma grande mudança na administração das escolas, em que a gestão passa a ganhar mais responsabilidades nos processos administrativos dos estabelecimentos.

A tese, de autoria de Falcão (2011), "A gestão democrática dos recursos financeiros nas escolas do município de Dourados (MS) 2005-2008", do Programa de Pós-graduação da Faculdade de Educação da Universidade de São Paulo (USP), objetivou analisar as políticas de descentralização de recursos financeiros, enfatizando as normas de gestão democrática e ressaltando que as mesmas trazem consigo concepções de poder, sociedade, democracia e função social da escola. Os resultados da pesquisa demonstraram que embora a política de descentralização se configure em uma importante ferramenta para auxiliar nas decisões na escola, não se ampara na efetiva participação da comunidade como princípio de democratização do espaço escolar.

A dissertação de mestrado intitulada "A Gestão das Políticas Educacionais Municipais: a experiência da rede pública municipal de Alto Alegre do Pindaré - MA", de Santos (2011), foi produzida junto ao Programa de Pós-graduação em Educação da Universidade Federal do Maranhão. Constitui-se de uma pesquisa qualitativa a qual objetivou debater sobre a gestão das políticas educacionais municipais, tendo como referência a experiência da Rede pública Municipal de Alto Alegre do Pindaré - MA e os principais movimentos históricos e marcos legais no âmbito educacional no Brasil. O estudo revelou a importância de os sujeitos conhecerem as necessidades das escolas e a concepção de gestão democrática. Outro ponto relevante é a necessidade de investir na formação inicial e continuada dos docentes, inclusive dos gestores escolares.

A dissertação "Democracia e política na gestão educacional: limites e perspectivas de uma gestão democrática", de autoria de Silva (2013), do Programa de Pós-graduação em Educação da Universidade Federal de Pernambuco, foi realizada via estudo de caso de cunho qualitativo. Teve por objetivo analisar o processo de democratização da gestão educacional no Sistema Municipal de Ensino de Abreu e Lima no estado de Pernambuco. A autora enfatiza as relações de poder nos processos de gestão educacional do município em inter-relação com os professores da Rede Municipal de Ensino. Tal realidade foi marcada pela criação do sindicato da categoria, que traz mudanças com relação a melhores condições de trabalho e a garantia de direitos e democratização da gestão, possibilitando o acesso e a participação coletiva. Como resultados, constatou-se que as práticas vivenciadas na gestão educacional municipal são pautadas por uma cultura centralizadora, gerando limitações para a efetivação de processos de gestão democrática. 


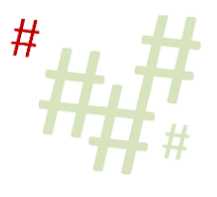

A pesquisa de mestrado profissional "Plano de ações articuladas na gestão da educação de municípios pertencentes à associação dos municípios da zona da produção (AMZOP)-RS", de autoria de Cichelero (2018), foi desenvolvida junto ao Programa de Pós-graduação em Políticas Públicas e Gestão Educacional da Universidade Federal de Santa Maria. Trata-se do estudo de casos múltiplos de natureza qualitativa que objetivou analisar os limites e possibilidades trazidos pelo Plano de Ações Articuladas (PAR) para a gestão da educação de municípios pertencentes à regional AMZOP-RS. A partir das contribuições dos colaboradores da pesquisa (dirigentes municipais na pasta de educação) a autora articulou uma proposta de curso de formação continuada sobre financiamento da educação, gestão democrática e o plano de ações articuladas, como alternativa para fortalecer a gestão dos Sistemas Municipais de Ensino nesta regional.

A tese de doutorado "Gestão democrática escolar: uma experiência em duas escolas públicas na rede municipal de João Pessoa-Paraíba", de Silva (2018), defendida no Programa de Pós-graduação em Educação da Universidade Federal da Paraíba, teve por objetivo analisar como ocorre o processo de gestão democrática em duas escolas na Rede Municipal de Ensino de João Pessoa, Paraíba. Consistiu num estudo de caso, com base em entrevistas com gestores e participantes da comunidade escolar. Os resultados evidenciaram que a gestão democrática é possível de ser concretizada, desde que a comunidade esteja unida e sustente práticas de democracia por meio de mecanismos de participação que garantam processos colaborativos entre os sujeitos nos espaços da escola.

Uma característica relevante nos trabalhos selecionados é que grande parte consiste em estudos de casos, em que os pesquisadores atuam ou contribuíram em algum momento em contextos escolares e suas relações com a gestão educacional municipal, com exceção do trabalho de Cichelero (2018) que está focado na gestão educacional de uma regional do estado do Rio Grande do Sul. Os trabalhos selecionados no descritor 1 tinham como foco a democratização dos espaços educativos em âmbito municipal.

Por se tratar de pesquisas na área de educação, todos os trabalhos têm como ponto em comum a construção de uma linha histórica acerca do percurso das legislações no campo da educação no Brasil e o fato de todas abordarem a perspectiva dos princípios de democratização da gestão educacional e escolar, com destaque para: a) o processo de descentralização consiste na mudança de responsabilidade de uma esfera para outra, porém deveria ser compartilhado entre ambas as instâncias (NUNES, 2010); b) a política de descentralização se configura numa importante ferramenta para democratização do espaço escolar, entretanto para se concretizar precisa se amparar na efetiva participação da comunidade (FALCÃO, 2011); c) é indispensável que a comunidade escolar conheça suas reais necessidades e prioridades utilizando de mecanismos de gestão democrática para garantir processos participativos e colaborativos em prol de melhorias nos espaços escolares (SANTOS, 2011; SILVA, 2018); d) torna-se indispensável criar uma cultura de constante investimento na formação inicial e continuada dos docentes e gestores para fomentar qualidade e gestão educacional e escolar democrática (SANTOS, 2011; CICHELERO, 2018); e) a criação do sindicato da categoria docente potencializou mudanças com relação a melhores condições de trabalho e a garantia de direitos e democratização dos processos de gestão, em contraponto às práticas na gestão educacional centralizadoras (SILVA, 2013). 


\section{Mecanismos de democratização da gestão relacionados aos Sistemas Municipais de Ensino}

Entende-se por mecanismos de democratização da gestão educacional os meios pelos quais constituem um exercício participativo dos sujeitos, tornando possível a discussão e atuação nos contextos educacionais, sejam eles macro ou micro, e a forma equitativa e coletiva de tomada de decisões e de coparticipação pelos envolvidos. Por exemplo, conforme Paro (2000), a exigência de mecanismos institucionais se deve ao fato de propiciar e incentivar práticas participativas no contexto da escola.

Destaca-se como mecanismos que potencializam a democratização dos espaços educacionais: dispositivos de autonomia financeira na secretaria de educação e nas instituições escolares, contando com a gestão colegiada de recursos financeiros; a escolha de diretores nas redes de ensino públicas; a existência e atuação proativa órgãos colegiados, entre eles o conselho escolar e o conselho municipal de educação; a construção e consecução participativa do projeto político-pedagógico (PPP) e regimento escolar, entre outros.

A gestão de recursos financeiros é um dos dispositivos de gestão compartilhada com maior atenção pela comunidade escolar, por se tratar de dinheiro público. Esta tarefa demanda tempo e dedicação dos gestores e dos membros do conselho escolar que atuam de forma conjunta neste processo. A autonomia administrativa assegurada na LDB n. 9.394/96, artigo 14, estabelece que os sistemas de ensino tomem as decisões de acordo com suas especificidades, incluindo a utilização dos recursos financeiros (BRASIL, 1996).

A escolha de diretores é outro dispositivo de grande importância e a forma que é concretizado pode repercutir nos rumos da gestão escolar. De acordo com Paro (2003) há categorias de provimento do cargo de gestor escolar, no contexto da educação pública: a) nomeação; b) concurso; c) eleição ou de forma mista (integrando duas categorias de escolha). $\mathrm{O}$ autor coloca que a eleição é considerada a melhor forma de escolha, pois constitui-se um instrumento de participação da comunidade e, portanto, de direcionamento para processos mais coletivos e decisivos para que a gestão democrática possa ser efetivada nas escolas.

O Círculo de Pais e Mestres (CPM) e/ou Associação de Pais e Mestres (APM) e o Conselho Escolar, consistem em mais um dos mecanismos de participação da comunidade escolar. O Plano Nacional de Educação (BRASIL, 2014) prevê o fortalecimento destas entidades, bem como dos grêmios estudantis, podendo estas possuírem normas próprias em seus estados e municípios. Assim, destaca-se a importância destes órgãos colegiados para a aproximação das famílias, comunidades e instituições educativas, tornando viável a espaços de democratização da gestão por meio da participação representativa, das decisões coletivas e processos corresponsáveis e compartilhados de consecução das mesmas.

O projeto político-pedagógico (PPP) e o regimento escolar são documentos norteadores que embasam o currículo escolar e o tripé administrativo, pedagógico e financeiro dos contextos escolares. O PPP estabelece diretrizes para fortalecer o desenvolvimento da educação de acordo com a realidade e identidade de cada instituição. A construção do PPP implica na participação e protagonismo da comunidade escolar, de modo que seja possível diagnosticar as demandas e, sobremaneira, pensar nas prioridades, estratégias e ações educacionais com vistas a qualidade dos processos administrativos e pedagógicos no contexto escolar.

Nessa direção, selecionou-se oito trabalhos referentes ao descritor 2 - mecanismos de democratização and gestão educacional, e foi possível fazer um levantamento sobre os principais mecanismos legitimados no contexto da gestão democrática, tendo por base que: "Princípios e mecanismos configuram, portanto, o que denominamos de condições político- 
institucionais de participação para a democratização da gestão educacional no âmbito dos sistemas municipais" (NARDI, 2018, p. 130).

A pesquisa de mestrado "As interfaces dos Conselhos Escolares do Sistema Municipal de Ensino de João Pessoa”, de Lelis (2010), desenvolvida no Programa de Pós-graduação em Educação da Universidade Federal da Paraíba, objetivou investigar os conselhos escolares do Sistema Municipal de Ensino de João Pessoa/PB, tendo como finalidade analisar a atuação dos mesmos. Tal estudo, de abordagem qualitativa, utilizou o método exploratório e descritivo para os dados da pesquisa. Nas análises a autora descortina que a atuação dos conselhos se distancia do que é proposto e, desta forma, necessitam realizar mudanças e assumir o seu papel como órgãos colegiados de participação e representação socioeducacional e, portanto, colaborativos, com vistas a contribuir para a descentralização do poder e a democratização dos espaços escolares.

$\mathrm{Na}$ dissertação "Fortalecimento de Conselhos Escolares: propostas e práticas em municípios sul-mato-grossenses", de Alves (2010), defendida no Programa de Pós-graduação em Educação da Universidade Federal da Grande Dourados, objetivou-se analisar a política nacional de fortalecimento dos conselhos escolares, enfatizando a atuação deles nos municípios sul-mato-grossenses. Sobre o impacto dos conselhos escolares nesta região, o autor concluiu que sua atuação, embora seja de grande importância para o fortalecimento da gestão democrática, não é uma prioridade para as redes escolares. O foco está no interesse pelo desempenho escolar e na busca de melhores resultados em avaliações externas com vistas à melhoria do Índice de Desenvolvimento da Educação Básica (IDEB) e à formação de professores.

A dissertação "Democracia, participação e controle social nos Conselhos Municipais de Educação", autoria de Moura (2010), do Programa de Pós-graduação em Educação da Universidade Federal da Paraíba, teve por objetivo analisar o funcionamento dos Conselhos Municipais de Educação (CME), no processo de democratização dos Sistemas Municipais de Ensino (SME), considerando a participação e o controle social. O estudo de casos múltiplos foi realizado em 14 municípios da microrregião de Guarabira, Paraíba. Traz os principais marcos de ruptura da gestão centralizada e burocrática que limitava os municípios e as escolas em sua autonomia. Os resultados da pesquisa demonstram que a relação entre o poder executivo e os conselhos inviabiliza a atuação dos órgãos colegiados e restringe a participação dos representantes da sociedade, devido à falta de estrutura para funcionamento do CME e, consequentemente, dificultando a gestão educacional.

A dissertação "Os Conselhos Municipais de Educação: o caso do município de São José dos Pinhais", de Moreschi (2010), do Programa de Pós-graduação em Educação da Universidade Tuiuti, Paraná, realizou um estudo sobre o Conselho Municipal de Educação no município de São José dos Pinhais-PR, propondo como reflexão o papel do conselho enquanto órgão colegiado que compõe o Sistema Municipal de Ensino. Com base na abordagem qualitativa e levantamento bibliográfico, o estudo focou a criação dos conselhos, suas atribuições e funções deliberativas com o poder para decidir sobre questões como: currículo, regimento escolar, projeto político-pedagógico, entre outras. A pesquisa demonstrou que os CME, de maneira geral, possuem algumas predisposições, sendo que ausência de autonomia e conselheiros capacitados, dependência do executivo municipal e carência na infraestrutura são os principais pontos destacados.

A pesquisa de mestrado intitulada "A eleição para diretores em Aparecida de Goiânia e a gestão democrática: desdobramentos na gestão da escola", de Moraes (2016), do Programa de Pós-graduação em Educação da Universidade Federal de Goiás, objetivou a análise quanto 
ao processo de eleições de diretores. A autora aponta que o modelo de gestão democrática não pode se restringir a assembleias, reuniões e eleições. A escola precisa priorizar a formação integral dos sujeitos com vistas à convivência em sociedade. Com a pesquisa, verificou-se que há algumas limitações quanto à escolha de dirigentes escolares, as quais destacamos o lento processo de conscientização sobre a importância da democratização e a influência política local no processo de indicação de dirigentes, ainda muito presente em nosso país. No entanto, o processo de eleição precisa ser entendido como momento de escolha de representantes e, nesse sentido, aprimorado, pois constitui-se como mecanismo para a efetivação da gestão democrática pelo viés da autonomia escolar.

A tese "Gestão democrática: o processo de representação nos Conselhos Escolares na rede pública municipal de São Luís, MA”, de Dublante (2016), do Programa de Pós-graduação em Educação da Universidade Federal do Rio Grande do Norte, objetivou analisar as práticas instituídas no processo de representação dos conselhos escolares em escolas públicas, enfatizando as influências de reformas estaduais no âmbito da educação no município de São Luís-MA. O autor sinaliza que os representantes do conselho e da comunidade não conhecem suas atribuições e não avaliam as atividades desenvolvidas na e pela escola. Constata que um dos principais desafios é a falta de articulação dos conselheiros e o despreparo para a função. Sugere incentivar e melhorar a qualidade das relações do Conselho com as comunidades escolares e secretaria, considerando-o um espaço de reflexão sobre as ações democráticas das escolas.

A dissertação "Os conselhos escolares no contexto do PAR (2007-2011): um estudo no município de Riachuelo/RN", de Santos (2017), do Programa de Pós-graduação em Educação da Universidade Federal do Rio Grande do Norte, objetivou investigar o processo de implantação dos conselhos escolares no município de Riachuelo-RN, tomando como base a gestão democrática e o Plano de Ações Articuladas (PAR) no período de 2007 a 2011. A pesquisa apontou que em função do município ser pouco desenvolvido, a implantação do PAR tornou-se uma alternativa de fortalecimento da educação municipal, centrando-se no desenvolvimento de ações para a implantação dos conselhos escolares. Resultou em melhorias efetivas nos indicadores da gestão democrática por meio da mobilização das comunidades escolares para a criação dos conselhos. O PAR constituiu-se um mecanismo de grande relevância proporcionando mudanças e resultados positivos nas redes de ensino, associado a uma gestão que prioriza o coletivo e a tomada de decisões de maneira compartilhada e corresponsável nas e pelas instituições.

A dissertação intitulada "O provimento ao cargo de direção escolar e suas implicações nos processos de gestão democrática da escola pública”, de autoria de Santos (2018), do Programa de Pós-graduação em Educação da Universidade Federal da Bahia, objetivou analisar o provimento ao cargo de direção escolar e suas formas de eleição e/ou indicação, assim como esses processos interferem na democratização da gestão da escola pública, no contexto do município de Jequié-BA. A pesquisa qualitativa revelou que o modelo gerencial tem favorecido o cenário de indicação de diretores para ocupar as funções de direção, no entanto, ao comparar com o cenário estadual, percebeu-se que o processo de escolha de diretores vem passando por mudanças, pois a eleição é colocada como etapa final do movimento de escolha. Apesar da forma de escolha ainda representar interesses específicos, destaca-se que há nas legislações municipais de ensino o pressuposto de que a eleição ou escolha de diretores constitui-se uma alternativa de preservar a autonomia escolar.

Os trabalhos selecionados no descritor 2 concentram-se na temática dos mecanismos de democratização da gestão relacionados aos Sistemas Municipais de Ensino, os quais são fundamentais para a concretização da gestão democrática. As pesquisas mostraram tais 
mecanismos e o quanto cada um interfere na cultura organizacional dos e nos contextos educativos. Destaca-se a importância da participação e protagonismo das comunidades escolares via órgãos colegiados, os quais possuem potencial para representar os interesses das comunidades escolares e interferir compartilhadamente nos rumos da educação pública.

Alguns resultados das pesquisas mencionadas merecem destaques, entre eles: a) órgãos colegiados contribuem com a participação e representação socioeducacional e, portanto, para a descentralização do poder e a democratização dos espaços escolares (LELIS, 2010; ALVES, 2010); b) a relação de poder do executivo para com os CME e a carência na infraestrutura fragiliza a atuação desses órgãos colegiados e restringe a participação dos representantes da sociedade nos processos de gestão educacional (MOURA, 2010; MORESCHI, 2010); c) o processo de eleição precisa ser entendido como momento de escolha de representantes escolares, para efetivamente constituir-se como mecanismo de autonomia e gestão democrática (MORAES, 2016; SANTOS, 2018); d) é indispensável melhorar a qualidade do diálogo e das relações do CME com as comunidades escolares e Secretaria de Educação (DUBLANTE, 2016); e) a implantação do PAR contribuiu para o fortalecimento da educação municipal, com a implantação e fortalecimento dos conselhos escolares, mobilização das comunidades escolares na tomada de decisões compartilhadas e corresponsáveis (SANTOS, 2017).

\title{
5 Criação e fortalecimento dos Sistemas Municipais de Ensino na perspectiva da gestão democrática
}

A criação dos Sistemas Municipais de Ensino consiste num processo reflexivo acerca da necessária e importante autonomia das instâncias educacionais em âmbito municipal, considerando os processos de gestão educacional e escolar. Concretizar sobre a necessidade da autonomia nas instâncias educacionais municipais, sobremaneira, requer adoção de prioridades, metas e ações que estejam alinhadas aos princípios e mecanismos de democratização já mencionados e, sobretudo, a constituição de SME como impulsionador da construção de identidade, cultura organizacional e políticas públicas próprias. Bordignon (2009, p. 37) sinaliza que:

\begin{abstract}
A construção do Sistema Municipal de Educação constituirá processo de diálogo entre pessoas e instituições, fundado em estudos e reflexões sobre a concepção de educação e responsabilidades prioritárias do município. A definição prévia de princípios, de referenciais e de processos, ajudará a orientar e dar coerência ao processo de organização do Sistema.
\end{abstract}

Nessa lógica, o Sistema Municipal de Educação compreende um conjunto de órgãos e instituições compostos pela rede de escolas municipais (Educação Infantil e Ensino Fundamental), escolas privadas de Educação Infantil, Secretaria Municipal de Educação (SMED) e Conselho Municipal de Educação ${ }^{3}$ (CME), entre outras instituições conveniadas com a rede municipal de ensino. De acordo com a LDBN/96, os municípios têm autonomia para desenvolver os seus sistemas próprios e segundo o Art. 11, parágrafo único: “Os Municípios poderão optar, ainda, por se integrar ao sistema estadual de ensino ou compor com ele um sistema único de educação básica" (BRASIL, 1996).

\footnotetext{
3 Os CME possuem, em municípios com SME, funções consultiva, propositiva, mobilizadora, deliberativa, normativa e fiscalizadora, sendo responsáveis pela organização educacional local, juntamente com as Secretarias Municipais de Educação que possuem função de execução das políticas públicas educacionais.
} 
O PNE (2014/2024), Lei n. 13.005 de 26 de junho 2014, enfatiza a importância da criação de Sistemas Municipais de Ensino com base em legislação própria:

\begin{abstract}
Art. $9^{\circ}$. Os Estados, o Distrito Federal e os Municípios deverão aprovar leis específicas para os seus sistemas de ensino, disciplinando a gestão democrática da educação pública nos respectivos âmbitos de atuação, no prazo de 2 (dois) anos contado da publicação desta Lei, adequando, quando for o caso, a legislação local já adotada com essa finalidade. (Brasil, 2014)
\end{abstract}

A criação e implementação de legislações educacionais próprias, via constituição do SME e ampliação das funções e protagonismo do Conselho Municipal de Educação, visa melhorar a autonomia da educação municipal, tornando-se fundamental priorizar os princípios de gestão democrática comprometida não somente com resultados e avaliações externas, mas, sobremaneira, com a qualidade da educação e a aprendizagem dos estudantes.

$\mathrm{Na}$ pesquisa do estado do conhecimento, selecionou-se no descritor 3 - criação e fortalecimento de sistemas municipais de ensino, seis trabalhos que abordam o âmbito dos SME, sua organização nos contextos pesquisados e seu funcionamento na perspectiva de melhorar a autonomia dos municípios.

A dissertação “A política educacional paulista e o processo de municipalização - 19952008: gerenciamento de resultados e patrimonialismo", de Mello (2010), do Programa de Pósgraduação em Educação da Universidade Federal de São Carlos-SP, objetivou analisar as mudanças nos padrões de gestão dos sistemas públicos de ensino, propostos a partir da reforma educacional do estado de São Paulo. De acordo com a coleta de dados por meio de entrevistas, Mello constatou que as mudanças ocorridas na gestão educacional se devem à descentralização e avaliação do Sistema direcionado pelo Plano Diretor do Estado. Tais ações inviabilizam a autonomia e participação da população nas decisões das escolas, o que acaba enfraquecendo a organização do SME e a atuação dos órgãos colegiados.

A dissertação de Castro (2011), "O Sistema Municipal de Ensino: uma análise histórica em Feira de Santana, no período de 1990 a 1998”, do Programa de Pós-graduação em Educação da Universidade Federal da Bahia, objetivou compreender como aconteceu o processo de criação do Sistema Municipal de Ensino (SME) de Feira de Santana-BA. Constitui-se num estudo qualitativo, em que a autora ressalta sobre a importância de decisões compartilhadas com a comunidade acerca da criação do SME. Os resultados revelaram que historicamente a organização dos Sistemas nesta região é marcada por uma concepção autoritária e centralizadora de pensar e gestar a educação, desconsiderando os anseios e limitando decisões pelas comunidades escolares. Neste cenário há a predominância do poder executivo sobre os demais órgãos e instituições.

A tese intitulada "Sistema Municipal de Ensino: arena de confluências, rupturas e desafios na democratização da educação", de autoria de Oliveira (2012), do Programa de Pósgraduação em Educação da Universidade Federal de Santa Maria, objetivou analisar, sob a perspectiva do ciclo de políticas, como se dá o desenvolvimento do Sistema de Ensino no município de Santa Rosa-RS, a partir da concepção da gestão democrática. Este estudo consistiu em uma pesquisa qualitativa, do tipo estudo de caso, com base na escuta dos sujeitos que vivenciam desafios no cenário educacional no que tange a efetivação da gestão democrática. $\mathrm{O}$ autor percebeu que há uma grande preocupação quanto à ação coletiva no Sistema Municipal de Ensino e na tomada de decisões quanto à organização das políticas educacionais. No entanto, sugere que o espaço do SME seja de reflexão, em que os sujeitos possam pensar e reformular ações e condutas a fim de exercer a democratização das instituições educacionais e da sociedade. 
A tese "Relações intergovernamentais e o fortalecimento da gestão educacional no Sistema Municipal de Educação", de Terto (2017), do Programa de Pós-graduação em Educação da Universidade Federal do Rio Grande do Norte, objetivou compreender se as relações intergovernamentais e o Plano de Ações Articuladas (PAR) fortaleceram a gestão democrática na Rede de Ensino do Município de Riachuelo-RN. Adotou como metodologia a pesquisa documental e a realização de entrevistas. Com as análises o autor concluiu que o PAR foi projetado e executado com base em uma visão gerencialista, em que foram criadas novas formas de aplicação do plano. Todavia destaca que o PAR trouxe melhorias para o Sistema de Ensino, mas ainda necessita qualificar nos espaços educativos a participação e a democratização. Sobre a gestão democrática enfatiza que a mesma possui um longo caminho até sua consolidação.

A dissertação de Soares (2017), "Gestão democrática: uma análise das bases normativas dos Sistemas Municipais de Educação do Maranhão", do Programa de Pós-graduação em Educação da Universidade Federal do Maranhão, teve como objetivo analisar como se expressa a gestão democrática na rede pública de ensino e nos textos legais que regulamentam os Sistemas Municipais de Ensino do estado do Maranhão. A partir da revisão da literatura, foi constatado que os princípios da gestão democrática estão distantes da realidade pesquisada, todavia há um avanço significativo quanto à busca de autonomia e do fortalecimento dos Sistemas de Ensino do Maranhão.

A dissertação "A trajetória político-histórico-normativa do Sistema Municipal de Ensino de Barretos/SP (1996 a 2016): O papel do legislativo na implementação de programas e políticas públicas educacionais", de Cipriano (2018), do Programa de Pós-graduação em Educação Escolar da Universidade Estadual Paulista, objetivou identificar e analisar a trajetória histórica e político-normativa de criação e implantação do Sistema Municipal de Ensino de Barretos, com base em uma pesquisa documental a qual analisou legislações em âmbito nacional, estadual e municipal. Foi constatado que a educação neste município passou por distintos períodos de governos em que as decisões aconteciam por parte do poder executivo e seus representantes. Assim, algumas ações perderam suas características coletivas, passando por transformações à medida em que trocavam os governos, não havendo preocupação com a democratização nos processos de gestão educacional e escolar.

Os trabalhos discutidos no descritor 3 contemplam a temática sobre os Sistemas Municipais de Ensino, descortinando algumas problemáticas enfrentadas no contexto dos SME, entre elas, a centralização do poder, falta de autonomia e participação socioeducacional, direcionamento de políticas de governo na organização do SME, pouca proatividade dos CME e não valorização dos mecanismos de democratização da gestão. Todos os trabalhos selecionados sinalizam que não basta priorizar a criação do SME, uma vez que esse processo se consolidará democrático e fortalecido na medida em que considerar a efetivação dos princípios e mecanismos de democratização da gestão educacional e escolar.

\section{Considerações finais}

Este estudo, com base na realização da pesquisa do estado do conhecimento, viabilizou o mapeamento de produções científicas, no período de 2010 a 2019, referentes a democratização da gestão educacional e escolar no Brasil e suas contribuições quanto aos mecanismos de criação, fortalecimento e democratização dos Sistemas Municipais de Ensino.

As produções científicas selecionadas trouxeram, em suas particularidades, $\mathrm{o}$ conhecimento acerca de contextos locais diversificados demonstrando de forma detalhada o 
funcionamento dos SME e enfatizando aspectos positivos e as fragilidades que comprometem os processos democráticos na educação municipal. De modo geral, as pesquisas demonstraram que os SME são, por si só, peça fundamental para a conquista de espaços de democratização e qualidade da educação municipal, especialmente no que diz respeito ao princípio da autonomia. Entretanto, não basta somente a existência de SME e CME atuantes para concretização dos preceitos de gestão democrática; é importante que os gestores municipais tenham conhecimento e vontade política apartidária, bem como comprometimento com o coletivo da educação municipal, no sentido de definir compartilhadamente e representativamente as prioridades, metas e ações educacionais com as comunidades e envolvidos.

Sobre os mecanismos de democratização, destaca-se que ainda existem grandes desafios a serem superados, principalmente pelos Conselhos, como por exemplo, a participação efetiva e integral de todos os seus membros no que se refere às decisões para e pelo coletivo e a formação dos conselheiros que, segundo os resultados de algumas pesquisas selecionadas, ainda é muito frágil ou inexistente em alguns municípios. Cabe ressaltar, de acordo com Gadotti (1993, p. 9), quanto ao compromisso e as responsabilidades do CME, “[...] apesar as peculiaridades de cada comunidade, deve existir algo comum entre todos os Conselhos Municipais de Educação que é a vontade política coletiva de construir uma educação de qualidade para todos".

Sobre os princípios de democratização foi possível compreender que os mais discutidos e incidentes nos contextos da gestão educacional e escolar são a participação, autonomia, transparência e descentralização, os quais constituem concepções fundamentais e necessárias para que ações educativas coletivas e compartilhadas sejam efetivadas no cenário dos sistemas, redes e instituições educativas. Também, na perspectiva da viabilidade de criação e implantação dos Sistemas Municipais de Ensino, foi possível verificar que cada município possui suas especificidades e suas demandas e que cabe aos gestores e representantes educacionais locais diagnosticar, por meio de estudos e mapeamentos, sua viabilidade e implicações na existência e proatividade de sistema próprio. Porém, destaca-se que o SME constitui um espaço dialógico, participativo de decisões e deliberações locais para a normatização e consecução de ações autônomas e personalizadas para a educação municipal.

Portanto, acredita-se que incentivar os municípios a investir em seu processo de descentralização da gestão educacional e escolar, pela da criação do SME e protagonismo normativo e deliberativo do CME, parece ainda ser uma prioridade para a tão necessária educação de qualidade que respeite as particularidades de cada região, adequando as suas realidades locais. Além disso, não basta a criação e proatividade dos SME e respectivos conselhos e instituições; torna-se imprescindível que os atores sociais e educacionais que estejam envolvidos com tais instâncias normativas e deliberativas possuam conhecimento e formação adequada para contribuir de maneira proativa e competente com a construção e consecução de políticas públicas e processos de gestão da educação.

\section{Referências}

ALVES, Andréia Vicência Vitor. Fortalecimento de conselhos escolares: propostas e práticas em municípios sul-mato-grossenses. 2010. 166 f. Dissertação (Mestrado em Educação) - Universidade Federal Da Grande Dourados, Dourados, 2010. Disponível em: http://repositorio.ufgd.edu.br/jspui/handle/prefix/81 Acesso em: 28 fev. 2021.

BORDIGNON, Genuíno. Gestão e educação no município: sistema, conselho e plano. São Paulo: Ed. L/Instituto Paulo Freire, 2009. Disponível em: 
http://www.acervo.paulofreire.org:8080/jspui/bitstream/7891/3082/1/FPF_PTPF_12_079.pdf Acesso em: 18 mar. 2021.

BRASIL. Constituição Federal de 1988. Constituição da República Federativa do Brasil. Brasília: Senado, 1998 Disponível em www.planalto.gov.br . Acesso em: 12 mar 2021.

BRASIL. Lei n ${ }^{\circ}$ 9.394, de 20 de dezembro de 1996. Estabelece as diretrizes e bases da educação nacional. Brasília: Diário Oficial da República Federativa do Brasil, Poder Executivo, 23 dez. 1996. Disponível em: http://www.planalto.gov.br/ccivil_03/leis/19394.htm. Acesso em: 12 mar. 2021.

BRASIL. Lei no 13.005, de 26 de junho de 2014. Aprova o Plano Nacional de Educação para os próximos 10 anos. Diário Oficial da República Federativa do Brasil, Poder Executivo. Disponível em:<http://www.planalto.gov.br/ccivil_03/_ato2011-2014/2014/lei/113005.htm>. Acesso em: 05 mar. 2021.

CASTRO, Selma Barros Daltro de. O Sistema Municipal de Ensino: uma análise histórica em Feira de Santana, no período de 1990 a 1998. 2011. Dissertação (Mestrado) -

Universidade Federal da Bahia, 2011. Disponível em:

http://www.repositorio.ufba.br/ri/handle/ri/9021. Acesso em 05 mar. 2021.

CICHELERO, Silvana Maria Tres. Plano de ações articuladas na gestão da educação de municípios pertencentes à associação dos municípios da zona da produção (AMZOP) RS. Dissertação (Mestrado Profissional do Programa de Pós-Graduação em Políticas Públicas e Gestão Educacional) - Universidade Federal de Santa Maria, 2018. Disponível em: http://repositorio.ufsm.br/handle/1/16076._Acesso em: 04 mar. 2021.

CIPRIANO, Aparecido Donizete Alves. A trajetória político-histórico-normativa do sistema municipal de ensino de Barretos/SP (1996 a 2016): o papel do legislativo na implementação de programas e políticas públicas educacionais. 2018. Dissertação (Mestrado) - Universidade Estadual Paulista (UNESP), 2018. Disponível em: http://hdl.handle.net/11449/153722. Acesso em 05 mar 2021.

DUBLANTE, Carlos André Sousa. Gestão democrática: o processo de representação nos conselhos escolares na rede pública municipal de São Luís, MA. 2016. 336f. Tese (Doutorado em Educação) - Centro de Educação, Universidade Federal do Rio Grande do Norte, Natal, 2016.Disponível em: https://repositorio.ufrn.br/jspui/handle/123456789/22524 Acesso em: 04 jan 2021.

FALCÃO, Mary Sylvia Miguel. A gestão democrática dos recursos financeiros nas escolas do município de Dourados (MS) 2005-2008. Tese (Doutorado) - Faculdade de Educação de São Paulo (USP). São Paulo, 2012.Disponível em: https://teses.usp.br/teses/disponiveis/48/48134/tde-14052012 125403/publico/MARY_SILVIA_MIGUEL_FALCAO_cor.pdf Acesso em: 04 mar. 2021.

GADOTTI, Moacir. Sistema Municipal de Educação. In: GADOTTI, Moacir; ROMÃO, José Eustáquio. Município e Educação. São Paulo: Cortez: Instituto Paulo Freire; Brasília, DF: Instituto de Desenvolvimento de Educação Municipal, 1993. 
GIL, Antônio Carlos. Como elaborar projetos de pesquisa. 5. ed. São Paulo: Atlas, 2010.

IBICT. Biblioteca digital brasileira de teses e dissertações. Disponível em: <http://bdtd. ibict.br/vufind/>. Acesso em: 10 mar. de 2021.

LELIS, Lúcia de Fátima Gomes de. As interfaces dos Conselhos Escolares do Sistema Municipal de Ensino de João Pessoa. 2010. 130 f. Dissertação (Mestrado em Educação) Universidade Federal da Paraí-ba, João Pessoa, 2010.Disponível em:

https://repositorio.ufpb.br/jspui/handle/tede/4945 Acesso em: 10 jan. 2021.

LIBÂNEO, José Carlos. Buscando a qualidade social do ensino. In: Organização e Gestão da Escola: teoria e prática. Goiânia: Editora Alternativa, 2001. p. 53 - 60.

LIBÂNEO, José Carlos; OLIVEIRA, João Ferreira de; TOSCHI, Mirza Seabra. Educação escolar: políticas estrutura e organização. 2. ed. São Paulo: Cortez, 2008.

LUCK, Heloísa. A escola participativa: o trabalho do gestor escolar. Rio de janeiro: DP \& A editora, 2002.

LUCK, Heloísa. Gestão Educacional: uma questão paradigmática. Petrópolis, RJ, Vozes Série: Cadernos de gestão, 2006.

MELLO, Claudia Carnevskis de. A política educacional paulista e o processo de municipalização - 1995-2008: gerenciamento de resultados e patrimonialismo. $2010.95 \mathrm{f}$. Dissertação (Mestrado em Ciências Humanas) - Universidade Federal de São Carlos, São Carlos, 2010. Disponível em: https://repositorio.ufscar.br/handle/ufscar/2712. Acesso em: 10 mar. 2021.

MORESCHI, Elmari. Os conselhos municipais de educação: o caso do município de São José dos Pinhais. 2010. 111 f. Dissertação (Mestrado em Educação) - Universidade Tuiuti do Paraná, Curitiba, 2010. Disponível em: http://tede.utp.br:8080/jspui/handle/tede/1397 Acesso em: 10 mar. 2021.

MOROSINI, Marília Costa. Estado do Conhecimento: conceitos, finalidades e interlocuções.

Revista Educação Por Escrito, Porto Alegre, v. 5, n. 2, p. 154-164, jul.-dez. 2014.

Disponível em:

https://revistaseletronicas.pucrs.br/ojs/index.php/porescrito/article/view/18875/12399. Acesso em: 02 jan. 2021.

MOURA, Assis Souza de. Democracia, participação e controle social nos Conselhos Municipais de Educação. 2010. 167 f. Dissertação (Mestrado em Educação) - Universidade Federal da Paraí-ba, João Pessoa, 2010. Disponível em: https://repositorio.ufpb.br/jspui/handle/tede/4934. Acesso em: 02 jan. 2021.

MORAES, Luciana Martins de. A eleição para diretores em Aparecida de Goiânia e a gestão democrática: desdobramentos na gestão da escola. 2016. 155 f. Dissertação (Mestrado em Educação) - Universidade Federal de Goiás, Goiânia, 2016. Disponível em: http://repositorio.bc.ufg.br/tede/handle/tede/5625. Acesso em: 02 fev. 2021. 
PARO, Vitor Henrique. Por dentro da escola pública. 3. ed. São Paulo: Xamã, 2000.

PARO, Vitor Henrique. Eleição de diretores: a escola pública experimenta a democracia. São Paulo: Xamã, 2003.

Recebido em abril de 2021.

Aprovado em outubro de 2021. 